\title{
Retraction Note to: Perspectives for the long-term penetration of new renewables in complex energy systems: the Italian scenario
}

\author{
Alessandro Franco ${ }^{1} \cdot$ Pasquale Salza $^{1}$
}

Published online: 14 January 2016

(C) Springer Science+Business Media Dordrecht 2016

\section{Retraction Note to: Environ Dev Sustain (2011) 13:309-330 DOI 10.1007/s10668-010-9263-7}

This article has been retracted by the Editor-in-Chief due to severe and unexplained overlap in text and figures with "Strategies for optimal penetration of intermittent renewables in complex energy systems based on techno-operational objectives," (Received 29 April 2010, Accepted 28 July 2010, Available online 21 August 2010), an article authored by Franco and Salza in Elsevier's journal Renewable Energy. The articles were submitted to and under review by both Environment, Development, and Sustainability and Renewable Energy during overlapping periods, which violates the ethics policies of both journals. The article in Renewable Energy will remain in publication as the version of record.

The online version of the original article can be found under doi:10.1007/s10668-010-9263-7.

Alessandro Franco

alessandro.franco@ing.unipi.it

1 Dipartimento di Energetica “L. Poggi”, Università di Pisa, Largo Lucio Lazzarino, 2, 56126 Pisa, Italy 